\title{
Status Analysis on the Ability to Act of College Students' Career Planning
}

\author{
Shuting Tian ${ }^{1, *}$ \\ ${ }^{1}$ Academy of Fine Arts and Art Design, Mianyang Teachers' College, Mianyang, Sichuan 621000, China \\ *Corresponding author. Email: $422436041 @ q q . c o m$
}

\begin{abstract}
Career planning for college students is a special skill that can inspire self-cognition, improve employability, and understand the needs of the industry, thereby improving the viability and professional quality of college students in the job market. In fact, although most students have formulated their career planning, they lack the ability to execute, which leads to unclear personal career planning when facing future career trends. This article will analyze the status quo of the ability to act of college students' career planning, so as to guide students to take active actions to achieve their ideals and goals.
\end{abstract}

Keywords: College students, Career planning, Ability to act.

\section{INTRODUCTION}

The college period is the exploratory period of students' careers, the initial stage of gradually connecting career aspirations with their own conditions and social needs, and a critical period that affects the development of personal careers. The course of career planning for college students enables students to learn themselves, understand careers, and learn to plan, so as to provide theoretical and practical guidance for smoothly embarking on the job market in the future. However, many students don't pay enough attention to the career planning course and only want to pass the course examination, without realizing the important value of the course to guide practice. How should teachers make career planning truly a special skill for guiding students to plan rationally and enter the job market smoothly? The author believes that under the current new situation, in addition to guiding students to make reasonable career planning in career planning courses, teachers should also guide and improve the process and ability of students to implement the planning, that is, to enhance students' ability to act.

*Fund: This article is supported by the project of Mianyang Teachers' College (QD2013A05;MYSY2021YB07).

\section{OVERVIEW OF THE STATUS QUO OF THE ABILITY TO ACT ABOUT COLLEGE STUDENTS' CAREER PLANNING}

The ability to act of college students' career planning refers to the ability of college students to make detailed study plans for their ideal career goals and consciously and actively promote the achievement of their career goals, including the strength of the willingness to achieve the goal, the ability, and the effectiveness of the action.

In recent years, the author has been engaged in the teaching of career planning and employment guidance for college students, and conducted key researches on students of two grades and four majors in the Academy of Fine Arts and Art Design of the school by issuing questionnaires and classroom surveys. In the survey interview, more than $3 / 4$ of the students agreed that career planning can enhance the purpose and planning of individual development, and can promote personal competitiveness and success opportunities. However, the implementation effect of career planning was poor, and specific details were as follows. First, nearly $1 / 5$ of the students said that they never took action as planned even if they formulated a career plan. Second, more than 3/5 of the students encountered confusion when they acted in accordance with the career plan, instead of 
reassessing and adjusting the plan, they bypassed the problem, doubted and abandoned the plan, and followed the general trend forward. Third, about $1 / 5$ of the students said that they were acting in accordance with their career plan, but due to improper goal decomposition and lack of reasonable arrangements for the tasks to be done, the goal-guided actions were not effective.

Career planning has strong difference and orientation. Everyone must not only plan for themselves according to their own specific circumstances, combine scientific methods, and act according to certain procedures, and in practice, everyone also needs to make corresponding adjustments in accordance with changes in his or her own characteristics and social development. Therefore, career planning is a long-term, systematic and dynamic process.[1] Action is a prerequisite for achieving goals, and it is also the best way to test individual self-control. As the saying goes, "Even if it is the shortest road, it can't be reached without walking; even if it is a small task, it can't be completed without taking action", if one only makes a career plan without taking active action, the plan will become a mere scrap of paper and one's career goals won't be achieved.

\section{CAUSE ANALYSIS OF THE LACK OF ABILITY TO ACT OF COLLEGE STUDENTS IN CAREER PLANNING}

More than 4/5 of the students in the survey believed that laziness, poor self-discipline, and procrastination were "the main reasons hindering the implementation of career plans". There were also a small number of students who thought that unclear goals, dislike of majors, and inability to adjust plans in a timely manner were the reasons that hindered the implementation of career plans. In general, the students attributed their poor ability to act of career planning to subjective reasons. The author believes that the reasons for the lack of the ability to act of college students in career planning can be analyzed from the following levels.

\subsection{Insufficient Understanding of the Importance of Career Goals}

The goal is the result of an individual's behavior, a condition that satisfies the individual's subjective needs, and a driving force for the individual to act. Career goals are the core of career planning. A clear and reasonable career goal can prompt people to have a strong sense of mission and responsibility, act closely around the goal in their study and life, often check and revise the goal, maximize their potential, overcome doubts and fears, and achieve career goals in the process of progress.[2] In the course learning, a small number of students make short shrift of setting career goals as coursework. Most of the students fail to analyze their own actual situation in depth and determine the career goals that suit them; instead, they drift along, imitate others, and blindly pursue popular majors or set the expectations of family members as career goals. Such a career goal cannot satisfy the subjective needs of the individual, and its driving force and motivation are correspondingly weak. The individual's willingness to take action is not strong, and the degree of achievement of the goal is naturally not high. Unclear recognition of career goals and insufficient recognition of their importance are the key problems of lack of ability to act in career planning.

\subsection{Weak Individual Initiative and Self- control}

From a psychological point of view, initiative is a kind of stable behavior that individuals take the initiative to achieve goals, rather than relying on external forces, and self-control is the ability of individuals to control their emotions and behaviors. In the middle and high school stage, students are in a passive position to receive education, and entering a higher school is the only clear goal for teachers and students at this stage. After entering the university, students can freely decide the time and way of school life to a large extent, which requires students to have good initiative and selfcontrol, to be able to consciously and actively learn knowledge, participate in practice, and exercise their abilities so as to lay the foundation for future career development. But in fact, students are free from the pressure of compulsory study and sectional examination, and lose their motivation to study in the atmosphere of "hooray for passing". Some students lack a sense of learning goals and sense of crisis, in addition, the evaluation of students at the university level is no longer only grade-based. When faced with various temptations and interferences, students who lack initiative and self-control have a serious lack of awareness and ability to consciously act and cannot arrange their own school life reasonably. Career planning requires students to take the initiative and actively seek external support when they encounter setbacks. Even though some students are very clear 
about what they should do to achieve their career goals, they just can't take action and can always find all kinds of excuses for "not acting". As time passes, they feel regretful again and try to change but have no way to start, which eventually causes the planning to be stranded or delayed.

\subsection{Negative Effect of the Network Information Age}

In the Internet age, the Internet has played a huge role in helping students absorb knowledge, broaden horizons, and compensate for school education. The rich and colorful information resources and the convenient and quick way of dissemination and the popular elements of the new era have deeply attracted college students. However, the huge amount of network information is of varying quality, and all kinds of tempting audio-visual designs, big data intelligent push, and achievement experience can easily make some young students get short-term psychological satisfaction in online games, binge-watching, entertainment, social contact and online shopping, which can easily make them indulge in the "micro age" and fail to extricate themselves, relying more and more on the Internet. At the same time, they lose interest in various real-life activities, their learning energy is lax, their time and the knowledge they've learned are fragmented, and study and examination become their bywork. These students are content with the status quo and do not want to make progress, being indulgent and decadent in the leisure and comfortable environment created by them. Such a lifestyle of freedom from suffering and fatigue is eroding their thinking step by step, consuming their best years. Not knowing how to use various information platforms and smart terminals to promote personal development is an important external factor that hinders students' ability to act in career planning.

\subsection{Being Short of Effective Supervision and Evaluation Mechanism}

Career planning education in most colleges and universities is generally presented in the form of common required course, with short class hours, and lack of supervision and evaluation of students' later implementation of the planning. And the employment guidance center of the school focuses on intensive lectures to provide guidance service for graduates in job interviews, open recruitment examinations, etc., pays attention to the employment rate of graduates, and ignores the construction of a continuous and personalized career guidance service system for students' career development. The implementation of college students' career planning is mainly undertaken by counselors. To achieve personalized and professional career guidance, it requires not only the counselors to have professional knowledge and guidance capabilities, but also the awareness and actions of the students to actively seek help, so that career planning can proceed smoothly and effectively. In addition, there are currently no scientific reference system and standard for the strength of willingness, ability, and effectiveness of actions for students' career planning. At present, the employment rate that everyone attaches great importance to is far from enough to evaluate the effectiveness of career planning courses, the effectiveness of counselors' work, and the effectiveness of students' actions in implementing career planning.

\section{MEASURES TO IMPROVE COLLEGE STUDENTS' ABILITY TO ACT IN TERMS OF CAREER PLANNING}

It is imperative to improve college students' ability to act in terms of career planning. It needs to be guided from individual career goals, selfmanagement, network influence, and strengthening system construction, so as to promote students to use career goals as a guide to achieve a smooth transition to the job market.

\subsection{Carefully Setting and Reasonably Decomposing Career Goals}

Correct recognition and setting of career goals is the prerequisite and basis for improving the ability to act. Only the correct and appropriate career goals have great guiding significance for the individual's life, so that the individual can internalize the goal as a driving force to clarify the direction of his struggle and spend time and energy on the most important things to promote the smooth achievement of goals or at least save yourself from twists and turns. First, the goal must be in line with one's own reality. Based on the analysis of individual interest, personality, ability, and value, it is needed to set career goals based on the occupational environment. Second, the goal must meet the needs of society. Personal career goals are affected and restricted by social reality. It is necessary to combine personal ideals with social ideals so that personal goals have a certain degree 
of flexibility to adapt to changes in the social environment. Third, the students' ability must be improved to manage goals. Efforts should be made to break down career goals into stage goals, so that they can take positive action to achieve stage goals. When they encounter difficulties in action, they must take heart of grace and stimulate their potential to overcome them, know how to reevaluate and adjust their action plans, or actively seek outside support and assistance, so as to facilitate the realization of stage goals.

\subsection{Actively Cultivating Self-management Awareness and Ability}

After entering the university, college students should make timely self-adjustment, adapt to the new study and life, cultivate and exert selfmanagement ability, explore career goals and strive to achieve their goals. First, college students should start from target decomposition, inspire and cultivate self-management ability. First of all, they should list the reasons for their career goals, explore the internal drive to act, and let themselves take action, replacing negative thinking or laziness with action and busyness. Secondly, after reaching a small goal, they need to give themselves a suitable material or spiritual reward, and at the same time, feel the joy during the action attentively, summarize the gains and find the gap with the goal to promote the realization of the big goal. Second, they should make full use of peer role models to improve self-management effectiveness. They should look for excellent students with strong selfcontrol and ability to act as role models or learning partners, and set career goals and supervise each other through the encouragement of their peers in order to strengthen initiative and self-control, stimulate individual ability to act, experience selfworth in the process of achieving goals, and improve action willpower and self-efficacy. Third, they need to rationally use self-management software to strengthen the supervision of individual actions. In addition, improving the ability to act requires students to develop an adventurous spirit and a proactive attitude. Due to lack of adventurous spirit and the courage to overcome inertia, some students subjectively believe that the conditions for action are immature and inadequate, so they fail to take action. At the same time, they should check the results of actions in a timely manner, strengthen self-supervision, and ensure the consistency of action and planning.

\subsection{Reasonably Making Use of the Internet to Promote the Realization of Goals}

The Internet not only helps people learn and live better, but it is also full of all kinds of temptations. Some students rely too much on the Internet, which seriously affects their normal school life. In addition to enhancing the self-control ability of college students and achieving network selfdiscipline subjectively, teachers should make full use of the network platform to recommend professional learning platforms to students and expand their professional knowledge. The ideological and political education team of colleges and universities should play the educational management function, focus on the individual career goals of the students, cultivate students' selfmanagement ability through multiple paths, and guide students out of their comfort zone, rationally arrange their spare time, rationally use media resources, and integrate and process fragmented knowledge to enhance the core competitiveness of students' career development. The process by which students can proactively acquire knowledge and improve skills around career goals is an effective performance of the ability to act in terms of career planning.

\subsection{Setting up an Effective Supervision and Evaluation Mechanism}

In the education system for the growth of college students, the supervision and evaluation mechanism of students' career planning plays an important role in improving the level of college education management, improving the quality of student employment, and establishing a modern university system. Improving college students' ability to act of career planning requires students, teachers, and ideological and political educators in colleges and universities to work together for students to achieve their career goals under the promotion of the supervision and evaluation mechanism. The supervision and evaluation system should include the following levels. The first is the evaluation mechanism of career planning courses. Classroom teaching is a key link that directly affects the cultivation of talents. An effective evaluation mechanism can not only increase students' emphasis on course learning and enable them to achieve good learning results, but also have a more comprehensive understanding of teachers' teaching level, practical guidance, and teaching effects, thereby effectively guaranteeing the quality of teaching, promoting the professional 
development of the teaching team, and improving the teaching level of teachers. The second is to set up a career planning consulting group. The existing employment guidance center of colleges and universities should include career planning consulting services, hire professional career planners, expand the scope of services, and guide students to implement the plan effectively in the long-term, and then, employment goals will be naturally achieved. The third is that counselors should pay attention to the use of career planning to promote the healthy growth of students, which is also an important growth path for counselors to become professional.

\section{CONCLUSION}

Career planning is a career design in which individuals constantly adjust themselves, break through obstacles, stimulate potential, and realize the maximization of individual benefits in each stage while adapting to the possible changes. Career goals are the internal drive for individuals to take action, and the ability to act is the key guarantee for the realization of career planning. Only planning without action, all goals and ideals are empty talk. Therefore, college students must refuse to delay after formulating their career plans, and they need to take active actions to achieve their career goals smoothly.

\section{AUTHORS' CONTRIBUTIONS}

This paper is independently completed by Shuting Tian.

\section{REFERENCES}

[1] Guo Lin. Self-exploration and Selfmanagement $[\mathrm{M}]$. Chongqing: Chongqing University Press, 2018: 60-154. (in Chinese)

[2] Yu Changhu, Lv Zhenhua. Employment and Entrepreneurship and Career Planning of College Students [M]. Beijing: China Economic Publishing House, 2010:15-56. (in Chinese)

[3] Li Long, Li Chenguang, Chen Hengying. Mental Health Education for College Students [M]. Chongqing: Chongqing University Press, 2018: 26-45. (in Chinese)

[4] Liu Wenguo. Development and Application of Non-intellectual Quality: Self-education [M].
Qingdao: Ocean University of China Press, 2006:203-223. (in Chinese)

[5] Zhao Wentong, Goal Psychology, Don't Tell Others Before the Goal Is Achieved [M]. Beijing: The Chinese Overseas Publishing House, 2017: 25-216. (in Chinese)

[6] Shen Yimo. Mental Health Education for College Students [M]. Chongqing: Chongqing University Press, 2018:5-190. (in Chinese)

[7] Wang Shaozhen, Jiang Chunru. The Current Situation of Fragmented Learning of College Students and the Path of Teaching Reform [J]. Journal of Anhui Radio \& TV University, 2020,(2):48-51. (in Chinese)

[8] Wang Zhen, Xu Li, Zhang Xinpeng. A Preliminary Study on the Executive Power and Organizational Power of College Student Leaders in the New Era $[\mathrm{J}]$. The Science Education Article Collects, 2019,(12):35-37. (in Chinese) 